\title{
CELLULOSE NANOMATERIALS IN TEXTILE APPLICATIONS
}

\author{
ANDREA CRISTIANE KRAUSE BIERHALZ \\ Department of Textile Engineering, Federal University of Santa Catarina - Campus Blumenau, \\ Rua João Pessoa 2740, 89036-256, Blumenau, SC, Brazil \\ ¿ Corresponding author: A. C. Krause Bierhalz, andrea.krause@ufsc.br
}

Received August 1, 2021

\begin{abstract}
Nanocellulose (NCC) has attracted increasing attention for use in several applications owing to its impressive strengthto-weight ratio, ease of functionalization, and apparent biocompatibility. In the nanocomposite textile field, NCC has exhibited outstanding potential for reinforced fibers, especially fibers processed by solution spinning. Continuous NCC fibers with high modulus and strength can be obtained, while preserving the cellulose I crystal structure. Owing to the various possibilities of surface modification, NCC is an efficient adsorbent of cationic and anionic textile dyes, as it reaches maximum removal capacities comparable to those of commercial adsorbents. In dyeing, NCC contributes in improving dye fixation and reducing the consumption of chemicals and water. In this review, recent studies on the applications of NCC in the textile field are discussed. The main methods, advances and limitations, regarding the NCC applications for fiber reinforcement of water-soluble and insoluble materials, dye removal and textile finishing, are presented.
\end{abstract}

Keywords: cellulose nanocrystals, textile, fiber spinning, dye removal, finishing

\section{INTRODUCTION}

In recent years, nanotechnology has been significantly increasing the competitiveness of the textile industry. Nanomaterials of various classes, such as metal oxides and carbon nanotubes, can provide specific functionalities to conventional textile substrates, such as antimicrobial, antistatic, protection against ultraviolet radiation, flame retardancy, and self-cleaning., Nanotechnology has also contributed to improving the properties of fibers and fabrics, such as strength, softness, dyeability, color fastness, and durability. ${ }^{3}$

Among the wide range of available nanomaterials, nanocellulose (NCC) is excessively versatile and is used in several applications owing to its remarkable mechanical properties, which are related to its high modulus $(\sim 150 \mathrm{GPa}){ }^{4}{ }^{4}$ strength $(7.5-7.7 \mathrm{GPa})$, and low density $\left(1.6 \mathrm{~g} \mathrm{~cm}^{-3}\right){ }^{5}$ The Young's modulus of $\mathrm{NCC}$ is much higher than that of natural fibers, such as cotton $(12.6 \mathrm{GPa})$, flax $(27.6 \mathrm{GPa})$, jute $(26.5 \mathrm{GPa})$, sisal $(22 \mathrm{GPa}){ }^{6}$ and is higher than that of high-performance fibers, such as fiberglass $\left(\begin{array}{ll}50-80 & \mathrm{GPa}\end{array}\right)^{7}$ and aramid fibers $(\sim 67 \mathrm{GPa}){ }^{8}$ Furthermore, NCC is broadly biocompatible, chemically inert, has a low thermal expansion, good optical properties, and high chemical reactivity.
NCC is derived from renewable and widely available sources (wood, plants, algae, bacteria, and tunicates), and is biodegradable and recyclable. ${ }^{9,10}$ Significant environmental and economic benefits have also been associated with the use of agricultural and industrial wastes, such as corn husks, ${ }^{11}$ rice husks, ${ }^{12}$ and sugarcane bagasse $^{13}$ as NCC sources. Massive amounts of cotton fibers with high cellulose contents (up to $90 \%$ ) are annually processed in the industry. Therefore, textile cotton wastes are also a promising source of $\mathrm{NCC}^{14}$ These residues are obtained from different stages of cotton processing, such as ginning, carding, and weaving, or even from discarded clothes and fabrics. ${ }^{15,16}$ According to Wang et al., ${ }^{15}$ the production of NCC is an excellent alternative to recycle waste cotton cloths, which are mostly disposed in landfills or incinerated.

Cellulose consists of a linear homopolysaccharide composed of $\beta$-Dglucopyranose units linked together by $\beta-1-4-$ linkages, with amorphous and crystalline regions. It is the most abundantly produced homopolysaccharide, with an estimated annual production of $10^{11}-10^{12}$ tons cellulose biomass. ${ }^{17}$ The term "nanocellulose" refers to cellulosic materials with at least one dimension less than 
$100 \mathrm{~nm}$, which can be obtained when the amorphous regions are broken down by chemical, mechanical, or enzymatic treatments. ${ }^{18}$

NCC is categorized into two major groups: cellulose nanocrystals (CNCs) and cellulose nanofibrils (CNFs). ${ }^{19} \mathrm{CNCs}$ are rod-like (or needle-like) nanoscale materials (Fig. 1a), which are approximately 3-35 nm wide and 200-500 nm long, and are mainly obtained by acid hydrolysis with sulfuric acid. ${ }^{20,21}$ Figure 1(c) shows the appearance of a CNC suspension obtained by hydrolysis with sulfuric acid using cotton as cellulose source. The dimensions and properties strongly depend on the cellulosic source, preparation and processing conditions, and possible post- or pre-treatments. ${ }^{19}$ CNC suspensions, in general, exhibit high crystallinity, narrow size distribution, and good dispersibility owing to the negatively charged surface resulting from acid hydrolysis. ${ }^{10}$ Other terminologies employed to describe the rod-like materials include "cellulose nanocrystals", "cellulose nanowhiskers", "nanowires" and "nanorods". 22

CNFs, also called nanofibrils, nanofibrillated cellulose, microfibrillated cellulose, and nanofibrillar cellulose, ${ }^{23}$ have fibril-like features (Fig. 1b), with lengths of a few micrometers and diameters in the range of $5-50 \mathrm{~nm} .^{21}$ These nanomaterials are mainly produced using mechanical processes (high-pressure homogenization, grinding, microfluidization etc.) often associated with chemical or biological pretreatments. ${ }^{19,24} \mathrm{CNCs}$ are stiff owing to the predominantly crystalline regions; however, CNFs are flexible due to the entangled network with alternating crystalline and amorphous domains. $^{25}$ The CNC and $\mathrm{CNF}$ isolations are already well established at an industrial level, enabling excellent availability at an affordable cost.

Bacterial cellulose (BC) is also considered as belonging to the nanocellulose class and is characterized by high purity and crystallinity. It is produced extracellularly by bacteria (such as Acetobacter xylinum), cultivated in aqueous culture medium containing nitrogen sources and carbon sources, such as sugar. BC can be formed using a wide variety of substrates, and its properties, shape, and size, can be tailored during synthesis. $^{26} \mathrm{BC}$ is hydrophilic and free of lignin, hemicelluloses, or pectin. $\mathrm{BC}$ is suitable for a broad range of biomedical applications. ${ }^{21,27}$

These three classes of nanocellulose have been increasingly explored for different textile applications (Fig. 2). In filament or yarn production, NCC can act as the base element for continuous filaments of submicron diameter or as a reinforcement agent for nanocomposite structures with high mechanical resistance. In the case of $100 \%$ NCC filaments, unlike wellestablished regenerated cellulose, NCC maintains the cellulose I structure, which is much stiffer, compared to cellulose II. ${ }^{28}$

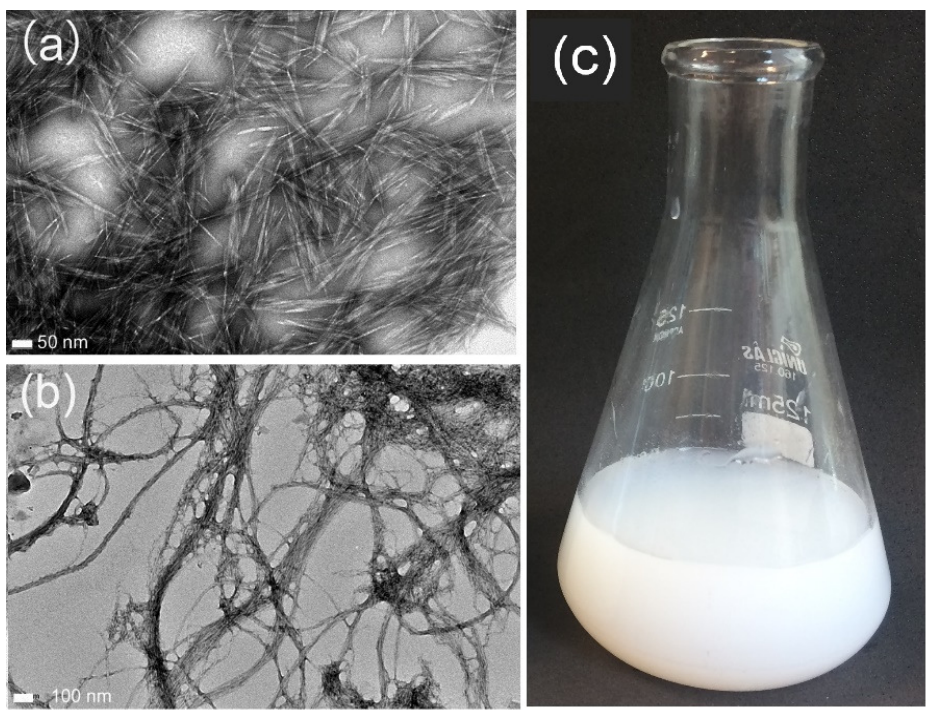

Figure 1: TEM images of (a) CNCs and (b) CNFs; and (c) aspect of CNC suspension after hydrolysis. Reprinted with permission (a and b) from Xu et al. ${ }^{20}$ (copyright 2013 American Chemical Society) 


\section{Cellulose sources}

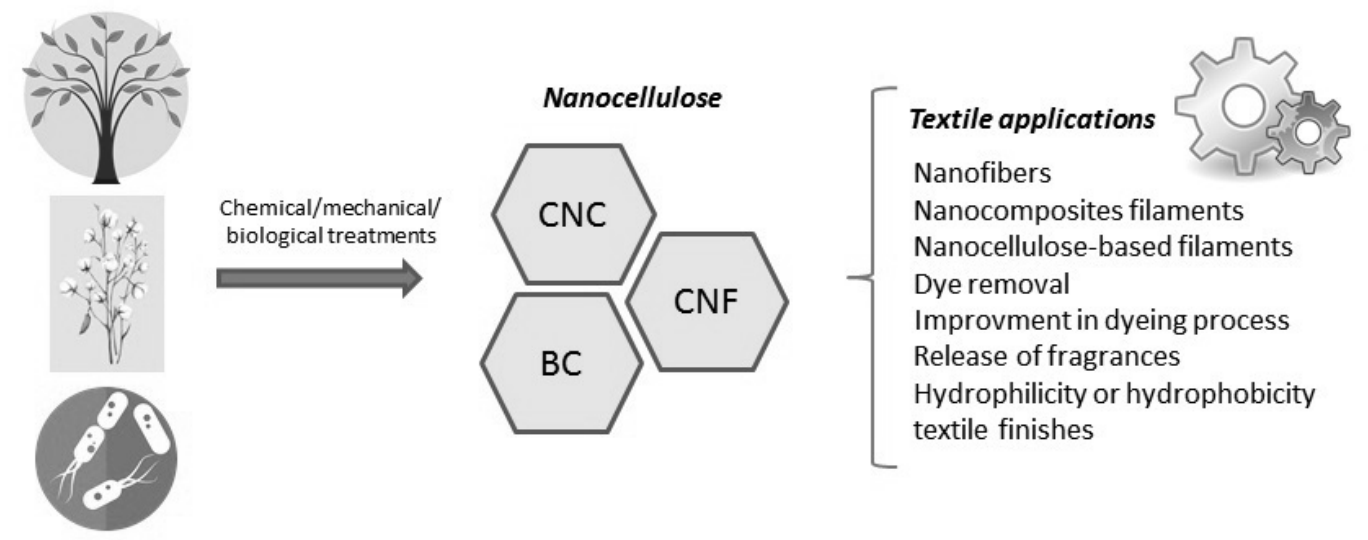

Figure 2: Sources, types of nanocellulose and textile applications

Fiber spinning includes melt spinning, solvent spinning (dry and wet spinning), and electrospinning. The limitations of melt spinning are mainly related to the dispersion of NCC in hydrophobic matrices. Therefore, several superficial modification methods have been proposed to increase the compatibility between NCC and polymers. NCC deposition methods are also beneficial for the mechanical properties of filaments or yarns obtained from natural fibers.

The high potential of NCC in the textile industry is not only due its outstanding mechanical performance. Due to the high concentration of surface functional groups and the possibility of chemical modification, NCC can strongly interact with various substrates. NCC is an excellent adsorbent for textile dyes, both cationic and anionic. Considering textile finishing, NCC is significant in more sustainable dyeing processes, as it reduces the consumption of dyes, water, chemicals, and dyes discharged in effluents. In addition, the hydrophilicity of synthetic substrates can be improved, which improves the perceived comfort of fabric. ${ }^{29}$ NCC can also impart superhydrophobicity to cotton substrates. ${ }^{30}$

According to the Google Scholar database, the number of scientific documents involving the keywords "nanocellulose" and "textile" increased from 168, in the period from 2000 to 2010 , to 7110 in the period from 2011 to $2020,84 \%$ of which were registered in the last five years (research carried out on 2/20/2021). These numbers reflect the increasing interest and strong tendency to expand the applications of NCC in the textile field.
In this review, the research progress involving the application of nanocellulose in the textile field in recent years is described in terms of three aspects: fiber spinning, textile finishing, and dye removal. In fiber spinning, important issues related to the processing and dispersion of NCC are discussed. The impact of NCC and modification treatments on the mechanical properties is also analyzed. In dye removal, the capacity of adsorption and strategies to increase the adsorption of cationic and anionic dyes of NCC is discussed, and this nanomaterial is compared to other adsorbents. The potential applications of NCC in textile finishing are also presented.

\section{FIBER REINFORCEMENT}

The addition of a second phase as a reinforcement in a polymeric matrix has been widely used to improve the mechanical properties of the developed materials and expand their applications in several areas. In fiber manufacturing, however, the success of this strategy is highly dependent on the size of the reinforcing element. Owing to the small diameter of the fibers, slight aggregation caused by macrosized elements can lead to spin failure. Nanosized materials have the potential to be used as a reinforcement phase, improving the mechanical properties of polymeric fibers, without affecting their spinnability and surface finish. ${ }^{31}$

Owing to its high modulus, high aspect ratio, and large surface area, NCC has been increasingly used to obtain fibers with new functionalities and improved mechanical properties. In addition to its outstanding properties, NCC offers advantages in 
terms of environmental friendliness and biological compatibility compared to other nanofillers, such as carbon nanotubes. ${ }^{32}$ Studies have demonstrated that nanocellulose can increase fiber stiffness and strength by over $100 \%$. $^{33-35}$

Nanocomposite fibers containing NCC have been produced using different spinning techniques, such as melt spinning, wet spinning, dry spinning (Fig. 3), and electrospinning. The choice of the method depends on the processing conditions and component characteristics, such as the melting point and degradation temperature. For all methods, achieving highly oriented nanofibrils is important because it results in more effective stress transfer and better mechanical properties. ${ }^{33}$ The main aspects of each technique involving NCC processing are addressed in the subsequent sections.

\section{Melt spinning}

Melt spinning is one of the most economical and convenient methods for continuous manufacturing of fibers from thermoplastic polymers in large quantities for the textile industry. ${ }^{28,37}$ In this technique, molten polymer is pumped through a spinneret under high pressure. Therefore, it is more environmentally friendly because it does not require solvents to dissolve the polymers. In addition, it is easily scalable and offers fiber drawing and heat setting to increase dimensional stability. ${ }^{31,35}$

A common limitation in obtaining composite fibers with NCC by melt spinning is its thermal degradation. Many polymers processed by melt spinning have a high melting point (above 200
${ }^{\circ} \mathrm{C}$ ), whereas the NCC extracted by sulfuric acidbased hydrolysis has a thermal decomposition temperature of approximately $180{ }^{\circ} \mathrm{C}$. The sulfate groups grafted and adsorbed to the surface of NCC are responsible for electrostatic repulsion and stability of suspensions, but they also catalyze thermal degradation. ${ }^{35}$ Thus, the applications involving fiber reinforcement with NCC by melt spinning have been limited to polymeric matrices with comparably low processing temperatures, such as polylactic acid (PLA) and acetate butyrate, as shown in Table 1.

However, thermoplastic polymers with low melting points tend to be hydrophobic, making homogeneous NCC dispersion in these matrices difficult to achieve. Therefore, the poor dispersion and incompatibility of CNCs with most nonpolar thermoplastics limit the final mechanical performance of these systems.

A variety of processing strategies have been adopted to minimize these dispersion and incompatibility issues, including solvent exchange and surface modification. ${ }^{40,41}$ The first study that used cellulose nanocrystals (CNCs) as an additive for melt-spun nanocomposite fibers was conducted by John et al. ${ }^{31}$ To avoid aggregation, the nanofibers in aqueous medium were solventexchanged to acetone, and a master batch of PLA with CNC was prepared for further melt spinning. No improvements in the mechanical properties were obtained by the addition of CNCs. According to the authors, this was caused by the poor dispersion of CNCs in the PLA matrix and lack of bonding between them.

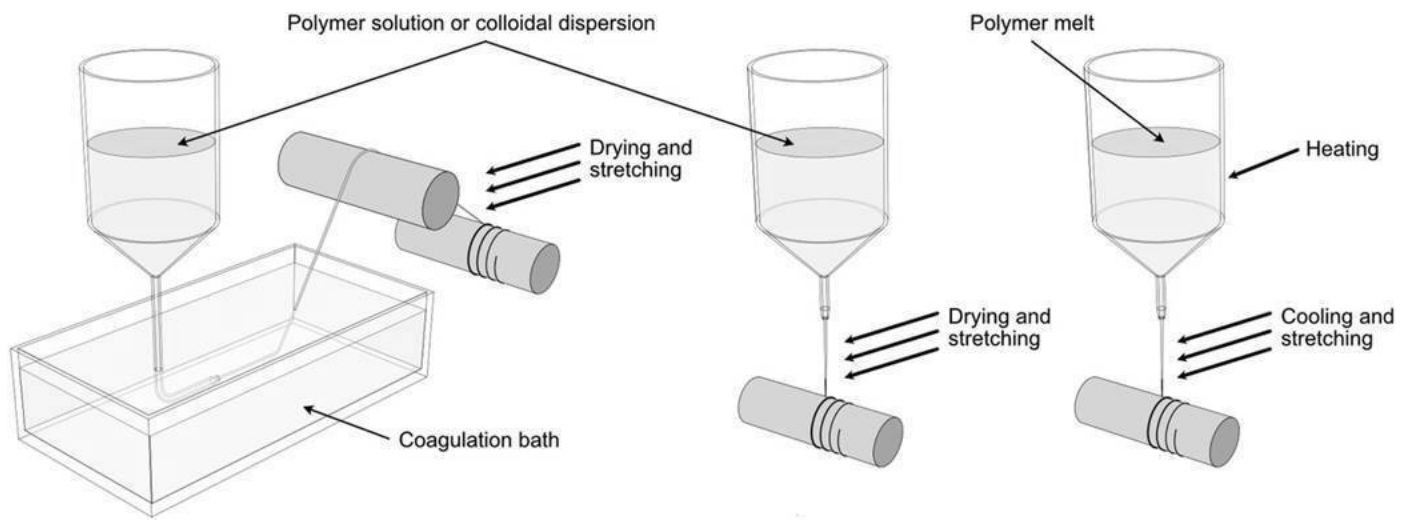

Figure 3: Common fiber spinning techniques: wet spinning (left), dry spinning (center), and melt spinning (right). Reprinted with permission from Rosén et al. ${ }^{36}$ (copyright 2020 Wiley Online Library) 
Table 1

Examples of nanocomposite fibers obtained by melt spinning and their mechanical properties

\begin{tabular}{|c|c|c|c|c|c|}
\hline Dispersion approach & Matrix & NCC source & NCC content & Main observations regarding mechanical properties & Ref. \\
\hline $\begin{array}{l}\text { Solvent-exchange to acetone by } \\
\text { centrifugation }\end{array}$ & PLA & $\begin{array}{l}\text { CNC extracted by acid } \\
\text { hydrolysis from } \\
\text { microcrystalline cellulose }\end{array}$ & $1-3$ wt $\%$ & $\begin{array}{l}\text { Presence of aggregates. Addition of } \mathrm{CNC} \text { did not improve tensile } \\
\text { strength of the fibers. Slight improvement in modulus was observed. }\end{array}$ & {$[31]$} \\
\hline $\begin{array}{l}\text { A masterbatch containing } 10 \mathrm{wt} \% \\
\text { CNFs in Nylon } 6 \text { was compounded to } \\
\text { improve the dispersion of CNFs } \\
\text { during subsequent processes }\end{array}$ & Nylon-6 & $\begin{array}{l}\text { Commercial spray-dried } \\
\text { CNF }\end{array}$ & $2.5-10 \mathrm{wt} \%$ & $\begin{array}{l}\text { Tenacity improved } 23.4 \% \text { ( } 10 \mathrm{wt} \% \mathrm{CNF}) \text {. } \\
\text { The elongation at break decreased from } 153.21 \% \text { to } 112.54 \% \text { and to } \\
69.5 \% \text { with the addition of } 5 \text { and } 10 \mathrm{wt} \% \text { of CNFs, respectively. } \\
\text { The moisture absorption of the nanocomposite filaments increased with } \\
\text { the addition of CNFs. }\end{array}$ & {$[32]$} \\
\hline $\begin{array}{l}\text { Polyethylene glycol (PEG) acted as a } \\
\text { compatibilizating agent; } \\
\text { Surface modification of CNF with 12- } \\
\text { carbon aliphatic chain (mCNF-C12) }\end{array}$ & PLA & $\begin{array}{l}\text { Mechanically fibrillated } \\
\text { CNF }\end{array}$ & $\begin{array}{l}0.05-1.3 \% \\
\text { mCNF-C12 }\end{array}$ & $\begin{array}{l}\text { Tensile strength of the fibers did not improve with the addition of CNC. } \\
\text { Stiffness was improved up to } 600 \%(1.3 \% \text {, maximum draw). }\end{array}$ & {$[33]$} \\
\hline CNC grafting with PLLA & PLA & $\begin{array}{l}\text { CNC extracted by acid } \\
\text { hydrolysis from commercial } \\
\text { cellulose microcrystals }\end{array}$ & $1 \mathrm{wt} \%$ & $\begin{array}{l}\text { Addition of } 1 \mathrm{wt} \% \text { CNC-g-PLLA resulted in improved stiffness }(\approx 20 \%) \text {, } \\
\text { strength }(\approx 100 \%) \text {, and elongation at break }(1720 \%) \text { compared to neat } \\
\text { PLA. }\end{array}$ & {$[34]$} \\
\hline $\begin{array}{l}\text { Dispersion of CNC in DMF by } \\
\text { sonication }\end{array}$ & $\begin{array}{l}\text { Thermoplastic } \\
\text { polyurethane } \\
\text { (PU) }\end{array}$ & $\begin{array}{l}\text { CNC extracted by acid } \\
\text { hydrolysis from tunicates }\end{array}$ & $1-5 \mathrm{wt} \%$ & $\begin{array}{l}\text { Incorporation of } 5 \mathrm{wt} \% \mathrm{CNC} \text { increased Young's modulus by } 500 \% \text { and } \\
\text { reduced the strain at break by } 60 \% \text {. }\end{array}$ & {$[35]$} \\
\hline $\begin{array}{l}\text { 1. Reduction and exchange water } \\
\text { content to ethanol using centrifugation } \\
\text { 2. Sol-gel process to exchange water } \\
\text { content of CNC by ethanol }\end{array}$ & $\begin{array}{l}\text { Cellulose acetate } \\
\text { butyrate (CAB) }\end{array}$ & $\begin{array}{l}\text { CNC extracted by acid } \\
\text { hydrolysis from } \\
\text { microcrystalline cellulose } \\
\text { and non-dried cellulose } \\
\text { residue (sludge) }\end{array}$ & $2 \mathrm{wt} \%$ & $\begin{array}{l}\text { 1. Agglomerates of CNC affected mechanical properties negatively. } \\
\text { Reduction of tensile strength, modulus and strain. } \\
\text { 2. Few aggregations of CNC. Young's modulus was improved by } 17 \% \\
\text { upon CNC addition. } \\
\text { Reduction of } 35 \% \text { in elongation at break. }\end{array}$ & {$[37]$} \\
\hline $\begin{array}{l}\text { BC modification with hexanoic acid } \\
\text { (C6-BC) and dodecanoic acid (C12- } \\
\text { BC) }\end{array}$ & PLLA & $\begin{array}{l}\text { CNC extracted by acid } \\
\text { hydrolysis from bacterial } \\
\text { cellulose }\end{array}$ & $\begin{array}{l}2 \mathrm{wt} \% \text { and } 7 \\
\text { wt } \% \text { (neat and } \\
\text { modified) }\end{array}$ & $\begin{array}{l}\text { PLLA fibers filled with } 2 \text { wt } \% \text { C6-BC exhibited the highest yield } \\
\text { strength. } \\
\text { Surface modification of BC with hexanoic acid, acted to improve the } \\
\text { draw ratio. }\end{array}$ & {$[38]$} \\
\hline $\begin{array}{l}\text { Compatibilizer } \\
\text { PLA } \square \text { grafted maleic anhydride } \\
\text { (PLA } \square g \square \text { MA) }\end{array}$ & PLA & $\begin{array}{l}\text { CNC extracted by acid } \\
\text { hydrolysis from commercial } \\
\text { microcrystalline cellulose }\end{array}$ & $1-3 \mathrm{wt} \%$ & $\begin{array}{l}\text { Addition of CNC did not improve tensile strength and Young's modulus } \\
\text { of the fibers. } \\
\text { Elongation at maximum force increased } \approx 18 \% \text { with } 1 \text { wt } \% \text { CNC } \\
\text { compared to neat PLA. }\end{array}$ & [39] \\
\hline
\end{tabular}


Hooshmand et al..$^{37,42}$ studied two different dispersion techniques to obtain homogenous melt spinning cellulose acetate butyrate (CAB) nanocomposite fibers. One approach consisted in reducing the water content of the $\mathrm{CNC}$ suspension and exchanging it with ethanol by centrifugation. In the second approach, the water in the CNC suspension was completely exchanged with ethanol by the sol-gel process. This technique increased Young's modulus by $17 \%$, without any surface modification or use of a surfactant. ${ }^{37}$ In a subsequent study, using this technique, nanocomposite fibers with a high concentration of CNC (10 wt\%), defectfree smooth surface, enhanced thermal stability, tensile strength $(23 \%)$ and modulus (90\%) were obtained. ${ }^{42}$

To increase the surface hydrophobicity of NCC and make it more compatible with polymers to be processed by melt spinning, a variety of surface modification methods have been developed. These methods include physical adsorption and chemical grafting of small molecules and macromolecules. ${ }^{43}$ For example, the superficial modification of bacterial cellulose with organic acids via esterification can improve its interfacial adhesion with PLLA, which improves the mechanical properties of the melt-spun fibers. ${ }^{8,38}$

Compatibilizers formed by the grafting of polymer chains on the surface of CNCs are promising to improve the interfacial adhesion between the CNCs and polymer matrix. To improve the compatibility between PLA and CNC, Mujica et al..$^{34}$ grafted PLLA chains onto the CNC surface using a "grafting from" reaction. A tensile strength improvement of $234 \%$ was reported for PLA nanocomposite fibers with PLLA-grafted nanocrystals, compared to the nanocomposites with neat CNCs. This results in a flexible interface between the grafted CNC and the PLA matrix, which offers high stretching and enhanced strength.

To increase the thermal stability and enable the processing of CNCs by melt spinning, Redondo et al. ${ }^{35}$ isolated CNCs from tunicates using phosphoric acid hydrolysis. The thermal analysis of the isolated material with phosphoric acid indicated an onset degradation temperature of approximately $300{ }^{\circ} \mathrm{C}$, while the CNC extracted with sulfuric acid showed an onset degradation temperature of approximately $180{ }^{\circ} \mathrm{C}$. The greater thermal stability can be attributed to the lower amount of degradation-catalyzing charged groups on the CNC surface. These CNCs were processed with thermoplastic polyurethane (PU) elastomer by melt spinning and were able to improve the Young's modulus of the fibers by more than $500 \%$.

In addition to mechanical reinforcement, nanocellulose has also been associated with the comfort of textile fibers by increasing their hydrophilicity. In general, the hydrophilicity of fibers provides a better feel and results in a more breathable product. Zhu et al..$^{32}$ studied the effect of CNF loading (0-10 wt $\%)$ on the properties of Nylon 6/cellulose nanofibril meltspun nanocomposite filaments. The authors observed that the incorporation of $\mathrm{CNF}$ improved the tenacity and initial modulus and increased the hydrophilicity of the nanocomposite filaments, which improved the fabric comfort.

Nanocellulose has also shown potential as a material with shape memory. Loads of $1 \mathrm{wt} \%$ $\mathrm{CNC}$ in shape memory polyurethane ribbons improved flexural properties and showed that they can act as springs incorporated in the material, offering a faster recovery rate and reduced recovery time. ${ }^{44}$

\section{Solvent spinning}

Solvent spinning can be classified as dry spinning or wet spinning. In these techniques, the polymer precursor is first dissolved to produce a spinning dope and then extruded through a forming element. The difference between dry and wet spinning is the form of solidification of the dope. In dry spinning, the solution is extruded through a spinneret into a warm air chamber, where the solvent evaporates and solidifies the fine filaments. In wet spinning, the solution is extruded and submerged in a liquid, where the solvent is removed through the diffusion of the fiber solvent to the baht solvent, or through precipitation by a chemical reaction. A combination of both wet and dry spinning, called the dry-jet-wet-spinning, has been increasingly used to obtain composite fibers with CNCs. In this approach, the spinning dope is extruded through an air gap between the spinneret and coagulation bath, where threadline tension can induce molecular orientation. $^{28}$ 
These spinning methods are used when the melt spinning is not possible, and when the final properties justify the increase in cost, time, and chemical risks related to solvents. ${ }^{33}$ In general, the solution processes result in improved mechanical performance, as they can result in highly drawn fibers. ${ }^{28}$

Studies based on solution techniques have focused primarily on synthetic and natural water-soluble polymers, such as PVA, ${ }^{45}$ alginate, ${ }^{46,47}$ methylcellulose, ${ }^{48}$ casein,${ }^{49}$ and silk fiboin. ${ }^{50}$ Nanocomposite fibers of other polymers, including cellulose acetate, ${ }^{51}$ PAN, ${ }^{52}$ and PLA $^{53}$ were processed using watermiscible organic solvents, such as acetone, dimethylformamide, and dimethylacetamide. In most cases, the addition of CNCs increased the mechanical properties of the individual fibers, as can be seen in Table 2. The molecular chain of the CNCs composed of glucose linked by $\beta-1-4$ glucosidic bonds resulted in hydroxyl groups on their surface, offering CNCs hydrophilic characteristics and compatibility with hydrophilic polymers. In addition, CNCs obtained from hydrolysis with sulfuric acid have sulfate groups on the surface, resulting in stable dispersions in water owing to repulsive interactions. ${ }^{47}$

\section{Electrospinning}

Electrospinning is a simple, versatile, and widely used technique for the production of ultrathin fibers. Owing to their high surface-tovolume ratio and interconnected and uniform porous structure, electrospun fibers have gained increasing prominence in applications involving filtration, sensing technology, energy generation, protecting clothes, tissue engineering scaffolds, and biomedical applications. ${ }^{55}$

The formation of nanofibers by this method is based on the uniaxial stretching of a viscoelastic solution by electrostatic forces. A typical electrospinning apparatus is composed of a spinneret (syringe needle) connected to a high-voltage supplier and a grounded metallic collector. The polymeric fluid (melt or solvent solution) is injected with a syringe pump through the spinneret at a controlled flow rate. When a high voltage (typically more than 5 $\mathrm{kV}$ ) is applied and the electrical potential exceeds the surface tension of the liquid, a filament is formed and ejected from the spinneret to the collector. The jet of the polymer elongates and dries during the trajectory, resulting in fibers that are deposited in the form of a nonwoven mesh. ${ }^{56}$

Several processing parameters can be used to control the diameter of the fibers, such as the viscosity of the polymer in solution, conductivity, surface tension, voltage, feed rate, distance between the spinneret and the collector, and the ambient temperature and relative humidity. Depending on the operating conditions and material properties, structural defects, such as beads, may be present in the resulting fibers. These defects lead to inefficient load transfer throughout the fiber and weaken the mechanical resistance of the membrane. ${ }^{57}$

In general, the CNC is added in small quantities to the polymer solution (1-5 wt \%), as there is a tendency of increasing viscosity, difficulty in spinnability, and of increasing diameter of the fibers. However, concentrations of up to $50 \%$ NCC have produced electrospun fibers. ${ }^{58}$

CNCs have been successfully processed by electrospinning using various natural and synthetic polymer matrices. When used as reinforcing phase, significant improvements in the mechanical properties were obtained with the CNC-polymer composites, compared to the neat polymer. For instance, the addition of 3 $\mathrm{wt} \% \mathrm{CNC}$ to electrospun fibers from hordein/zein increased the tensile strength and Young's modulus from $4.36 \pm 0.29$ to $7.79 \pm$ $0.36 \mathrm{MPa}$ and from $195.80 \pm 13.02$ to $396.64 \pm$ $18.33 \mathrm{MPa}$, respectively. ${ }^{59}$ The addition of only $0.105 \mathrm{wt} \%$ of CNC to cellulose acetate improved the fracture stress by 2.8 times and the fracture strain by 2.2 times, compared to the pristine $\mathrm{CA}$ nanofiber. ${ }^{60}$

$\mathrm{CNC}$-polymer interactions and the orientation of $\mathrm{CNCs}$ within electrospun fibers play an important role in their mechanical properties. Strong interactions between the matrix and $\mathrm{CNC}$ lead to efficient stress transfer within the composite fibers. The orientation of the nanocrystals along the fiber axis direction enhances the anisotropic mechanical properties. Electrospinning offers several advantages in terms of $\mathrm{CNC}$ alignment and the formation of nanocomposite fibers. The alignment is induced by large electric fields and shear forces in the liquid jet. Furthermore, owing to the small diameter, the removal of the solvent is very fast and contributes to the fixation of the fiber alignment. ${ }^{28,61}$ 


\section{ANDREA CRISTIANE KRAUSE BIERHALZ}

Table 2

Examples of nanocomposite fibers obtained by solution spinning and their mechanical properties

\begin{tabular}{|c|c|c|c|c|c|}
\hline $\begin{array}{l}\text { Spinning } \\
\text { technique }\end{array}$ & Matrix & NCC source & $\begin{array}{c}\text { NCC } \\
\text { content }\end{array}$ & Main observations regarding mechanical properties & Ref. \\
\hline Wet spinning & Alginate & $\begin{array}{l}\text { 1. CNC extracted by acid } \\
\text { hydrolysis from bleached birch } \\
\text { kraft paper } \\
\text { 2. Oxidized derivative (OCNC) }\end{array}$ & $0.5-8 \mathrm{wt} \%$ & $\begin{array}{l}\text { CNC is more effective than OCNC to improve mechanical properties. } \\
\text { The tensile strength of modified fibers reached a maximum at } 0.5 \mathrm{wt} \% \\
\mathrm{CNC/OCNC} \mathrm{loading.} \\
\text { Elongation at break and maximum work at break increased by } 208 \% \text { and } 523 \% \\
\text { for alginate/CNC fibers. Tensile strength was improved by } 40 \% \text {. }\end{array}$ & [47] \\
\hline Wet spinning & $\begin{array}{l}\text { Methyl- } \\
\text { cellulose }\end{array}$ & $\begin{array}{l}\text { CNC extracted by acid hydrolysis } \\
\text { from Whatman® Grade } 1 \text { filter } \\
\text { papers }\end{array}$ & $0-3 \mathrm{wt} \%$ & $\begin{array}{l}\text { Pure methylcellulose did not allow fiber spinning and the optimal mechanical } \\
\text { properties were achieved with } 0.25 \mathrm{wt} \% \mathrm{CNC} \text {. This condition resulted in high } \\
\text { strain }(36.1 \%) \text { and modulus of toughness }\left(48.3 \mathrm{MJ} / \mathrm{m}^{3}\right) \text {, keeping a high strength } \\
(190 \mathrm{MPa}) \text {. }\end{array}$ & {$[48]$} \\
\hline Wet spinning & Casein & $\begin{array}{l}\text { CNC particles on dry sodium } \\
\text { form }\end{array}$ & $0-37.5 \mathrm{wt} \%$ & $\begin{array}{l}\text { The maximum tenacity of } 5.84 \pm 0.16 \mathrm{cN} \mathrm{tex}^{-1} \text { was achieved at } 10.5 \% \text { of } \mathrm{CNC} \text {. } \\
\text { At this CNC content, elongation at break was reduced from } 86.1 \% \text { to } 3.93 \% \text {. } \\
\text { Young's modulus increased by } 34 \% \text {. }\end{array}$ & [49] \\
\hline Wet spinning & $\begin{array}{c}\text { Silk } \\
\text { fibroin }\end{array}$ & $\begin{array}{l}\text { CNC extracted by acid hydrolysis } \\
\text { from waste mulberry branch bark }\end{array}$ & $1-7 \mathrm{wt} \%$ & $\begin{array}{l}\text { Young's modulus, tensile strength and breaking strain were improved by } 195 \% \text {, } \\
160 \% \text { and } 130 \% \text {, respectively, with } 5 \mathrm{wt} \% \text { CNC. }\end{array}$ & {$[50]$} \\
\hline Dry spinning & $\begin{array}{l}\text { Cellulose } \\
\text { acetate }\end{array}$ & $\begin{array}{c}\text { Water-based suspensions of } \\
\text { CNCs (solvent exchanged into } \\
\text { N,N-dimethylacetamide (DMAc)) }\end{array}$ & $0-49 \mathrm{wt} \%$ & $\begin{array}{l}\text { Maximum improvements were achieved at } 34 \mathrm{wt} \% \mathrm{CNC} \text {, with increases of } 137 \% \\
\text { in tensile strength and } 637 \% \text { in elastic modulus. }\end{array}$ & {$[51]$} \\
\hline Dry-spinning & PLA & $\begin{array}{l}\text { CNC slurry at } 11.8 \text { wt } \% \text { in water } \\
\text { (Solvent exchange from water } \\
\text { into DMF) }\end{array}$ & $0-5 \mathrm{wt} \%$ & $\begin{array}{l}\text { Fibers presented elastic modulus between } 2 \text { and } 6.5 \mathrm{GPa} \text { and a maximum } \\
\text { strength of } 100 \mathrm{MPa} \text {. } \\
\text { The increase in the CNC shifted the mechanical behavior of the fibers from } \\
\text { ductile to brittle. }\end{array}$ & {$[53]$} \\
\hline $\begin{array}{l}\text { Dry-jet-wet- } \\
\text { spinning }\end{array}$ & PVA & $\begin{array}{l}\text { CNC extracted by acid hydrolysis } \\
\text { from wood pulp and cotton }\end{array}$ & $0-20 \mathrm{wt} \%$ & $\begin{array}{l}\text { Maximum improvements in tensile strength and elastic modulus were achieved } \\
\text { with } 15 \mathrm{wt} \% \text { CNC. } \\
\text { Elastic modulus increased from } 3.24 \text { to } 10.76 \mathrm{GPa} \text { (wood) and } 14.31 \mathrm{GPa} \\
\text { (cotton). Tensile strength increased from } 100.01 \text { to } 230.86 \mathrm{MPa} \text { (wood) and } \\
274.38 \mathrm{MPa} \text { (cotton). In terms of reinforcing, cotton CNC exhibited better } \\
\text { properties than wood CNC. }\end{array}$ & {$[54]$} \\
\hline
\end{tabular}


The evaluation of mechanical properties is usually centered on electrospun nanocomposite mats in measurements using dynamic mechanical analysis or Instron tensile tests. The analysis of mats is easier and more accessible than that of individual fibers. ${ }^{28}$ However, it should be considered that structural properties, such as thickness, porosity, distribution and intersection of the fibers, influence the mechanical properties of the mat. To eliminate the effect of these parameters and to better understand the role of CNCs in the mechanical properties of PMMA electrospun fibers, Dong et al $^{55}$ investigated the nanomechanical properties of single composite fibers using nanoindentation. CNCs were incorporated into electrospun PMMA fibers with weights up to $41 \%$, and the results indicated a moderate improvement of approximately $17 \%$ in storage modulus with the first $17 \mathrm{wt} \% \mathrm{CNCs}$.

In addition to mechanical reinforcement, NCC contributes to the improvement in specific properties for different applications involving nanofibers. For biomedical applications, NCC has been associated with increased biocompatibility, cell attachment, proliferation, and migration, with no toxic responses. For example, Jia et $a l^{62}$ produced electrospun vascular tissue scaffolds based on cellulose acetate (CA) containing microcrystalline cellulose (MCC) and CNC. The CNC promoted cell attachment and a synergistic effect of MCC and CNC was observed, as scaffolds containing both particulates simultaneously exhibited enhanced cell viability and biocompatibility. Naseri et $a l^{58}$ observed that CNC increased the permeability of electrospun fiber mats based on chitosan-polyethylene oxide to $\mathrm{O}_{2}$ and $\mathrm{CO}_{2}$ by 20 -fold and 22 -fold, respectively. Higher gas permeation of wound dressings is critical, as it accelerates tissue regeneration and prevents the proliferation of anaerobic bacteria.

$\mathrm{CNC}$ also demonstrated the potential for smart electronic clothing applications. Ponnama et al. ${ }^{63}$ investigated the piezoelectric properties of cellulose nanocrystals (2 wt \%) and Fe-doped $\mathrm{ZnO}$ (2 wt $\%$ ) embedded as fillers in electrospun nanofibers of polyvinylidene fluoride hexafluoropropylene (PVDF-HFP). CNC played a significant role in enhancing the piezo potential. According to the authors, each CNC acted as an electrical dipole, and during compressive stress, the
CNC sensed a voltage and resulted in voltageinduced electrical polarization.

In polyvinylidenefluoride-cohexafluoropropylene (PVDF-HFP) electrified membranes for distillation applications, the addition of $\mathrm{CNC}$ narrowed down the pore size distribution and improved the liquid entry pressure (LEP), which ensured high salt rejection of the membranes in membrane distillation. ${ }^{64}$ For separation, the addition of 4 wt\% CNC to PVDF electrospun membranes resulted in a four-fold increase in the flux of the membrane. ${ }^{65}$

\section{Cellulose-based fibers}

Regenerated cellulose fibers can be obtained from cotton linter or wood by two main regeneration systems: direct dissolution process and derivatizing process. In direct dissolution, cellulose is directly dissolved in solvent without modification, while in the derivatizing process, the chemical structure of the starting cellulose is modified before dissolution. ${ }^{66}$

The viscose (xanthate) derivatizing process is the most traditional route for obtaining regenerated cellulose fibers with low cost and good mechanical properties. However, the byproducts generated by this process have been associated with serious environmental problems. ${ }^{67}$ The oldest direct dissolution process is the cuppramonium process, invented in the 1890s. In this process, cellulose is dissolved in an aqueous solution of cuprammonium hydroxide using auxiliary hazardous chemicals, such as ammonia and sulfuric acid. The cuppramonium process is in decline in several countries because of the high cost of dissolution and related environmental and health issues. ${ }^{66}$

Alternative and more recent processes include the dissolution of cellulose in the $\mathrm{N}$ methyl-morpholine- $\mathrm{N}$-oxide (NMMO) ${ }^{68} \mathrm{~N}, \mathrm{~N}$ dimethylacetamide (DMAc)/ $/ \mathrm{LiCl},{ }^{69}$ $\mathrm{NaOH} /$ urea aqueous solution, ${ }^{67} \mathrm{NaOH} /$ water $^{70}$ and ionic liquids. ${ }^{71}$

There has been increasing interest in synthesizing single components using only cellulose nanomaterials. This interest is due to the possibility of obtaining fibers with high rigidity and tenacity, since the hydroxyl groups on the surface of $\mathrm{CNC} / \mathrm{CNF}$ can form strong hydrogen bonds with each other. ${ }^{72}$

Textile fibers from regenerated cellulose, such as rayon (cuprammonium process) and 
Lyocel $^{\circledR}$ (NMMO process), have cellulose II crystal structure, while natural cellulose has cellulose I crystal structure. Because of the loss of hydrogen bonds, the Young's modulus of cellulose II crystals of regenerated cellulose $(88 \mathrm{GPa})$ is much lower than that of cellulose I $(130-150 \mathrm{GPa}){ }^{72}$ The cellulose I crystal structure can be retained by spinning $\mathrm{CNC} / \mathrm{CNF}$ yielding fibers with a high degree of crystal orientation, as well as high modulus and strength. ${ }^{72,73}$

Cellulose nanofibers are not soluble, but are highly dispersible in water. Thus, a suspension of cellulose nanofibers in water has a viscosity similar to that of the cellulose solution and non-flocculated uniformity. This suggests that the cellulose nanofiber suspensions are suitable for spinning. ${ }^{73}$

Cellulose fiber spinning was first performed by Iwamoto et $a l^{73}$ and Walther et $a .^{7}$ The first group prepared TEMPO-mediated oxidized wood and tunicate cellulose fibers by simple wet spinning (wet extrusion, coagulation, and drying). The fibers exhibited tensile strength of $\approx 300 \mathrm{MPa}$ and stiffness of $\approx 25 \mathrm{GPa}$. According to Walther et al., ${ }^{7}$ the stiffness was one order of magnitude larger than that of typical rayon fibers.

The $100 \%$ NCC fiber can be produced by wet or dry spinning. In wet spinning, the dispersion can be spun into a coagulation bath containing solvents, such as acetone, ethanol, methanol/water, THF, and isopropanol, where the fibers are formed by solvent exchange. According to Shen et al., ${ }^{74}$ the drawbacks of wet spinning are related to uncontrolled removal of water, which leaves the filament hollow.

The dry spinning approach has also been successfully used for preparing CNF filaments. Hooshmand et $a l^{75}$ used piston-driven extrusion (capillary rheometer) for dry-spun cellulose nanofibers (CNFs) based on banana waste. Shen et al. $^{74}$ developed a dry spinning method with an adhesion-controlled surface exhibiting low friction (slippery surface). This strategy eliminates the need for shrinkage control, allowing the wet filament to dry in a controllable manner.

TEMPO-mediated oxidation is a widely applied chemical pretreatment of cellulose for filament production. The reaction is performed under mildly alkaline conditions using sodium hypochlorite $(\mathrm{NaClO})$ as the primary oxidant and 2,2,6,6-tetramethylpiperidine-1-oxyl radical (TEMPO) as the catalyst. In this process, anionic carboxylate groups are introduced at the C6 primary hydroxyl groups of glucose units on the surface of the crystalline cellulose microfibrils. The negative charges introduced at the surface of cellulose fibers greatly reduced the energy required for their disintegration into individual fibrils with very small diameters (typically $3-5 \mathrm{~nm}$ ). ${ }^{28,76}$ Therefore, the tension applied on a CNF filament had a stronger aligning effect due to the elevated fibril aspect ratio. ${ }^{77,78}$ However, the high specific area and surface charge made the TEMPO-oxidized CNF filaments more sensitive to water, impairing the strength under wet conditions. $^{77}$

Several studies have demonstrated the significance of the high orientation of nanofibrils in achieving better mechanical properties. In general, the nanofibers are aligned in the fiber direction of the spun fibers at higher spinning rates. ${ }^{10,79}$ Iwamoto et al. ${ }^{73}$ observed that by increasing the spinning rate from 0.1 to $100 \mathrm{~m} / \mathrm{min}$, the mechanical properties increased from 8.4 to $23.6 \mathrm{GPa}$ and from 90 to $320 \mathrm{MPa}$, respectively. Hooshmand et al. $^{75}$ investigated the effect of $\mathrm{CNF}$ concentration on $\mathrm{CNF}$ alignment and mechanical properties of filaments. They observed that the modulus of the filaments increased from 7.8 to $12.6 \mathrm{GPa}$ and the strength increased from 131 to $222 \mathrm{MPa}$ when the lowest concentration and highest speed were used.

As a strategy to increase fiber alignment and mechanical properties, Tang et al. ${ }^{80}$ covalently grafted polyethylene glycol onto the surface of cellulose nanofibrils. This approach facilitated the alignment and compartmentalization of individual nanofibrils in cellulose ribbons. As a result, high tensile strength of $576 \pm 54 \mathrm{MPa}$ and modulus of 32.3 $\pm 5.7 \mathrm{GPa}$ were obtained. Håkansson et al. ${ }^{81}$ developed a wet-extrusion process combining hydrodynamic fibril alignment (millimetersized flow focusing) with a dispersion-gel transition to produce homogeneous and smooth CNF filaments. The highest strength was 490 $\mathrm{MPa}$ and the modulus was $17.6 \mathrm{GPa}$.

\section{Reinforcement of fibers and fabrics by deposition}

Filaments or yarns from natural fibers can also be treated with CNC suspensions to improve their mechanical properties, mainly 
strength. Cellulose nanofibrils (CNFs) and cellulose nanocrystals (CNCs) were used to improve the mechanical properties of tapes and yarns produced from hemp and flax slivers. Yarns and tapes were produced by soaking fiber strands in different nanocellulose suspensions, which exhibited considerably higher tensile properties in terms of strength and initial modulus than those of the controls. The flax tape treated with CNF that was ground for 100 min showed an improvement in strength of approximately 45 times over the control. $^{24}$

Habeish et al. ${ }^{82}$ evaluated the reinforcement of cotton and polyester/cotton blend fabrics $(50 / 50)$ by soaking the fabrics in padding liquor containing $\mathrm{CNC}$, with surface modifications of grafting and etherification at different concentrations. Several properties of the fabrics, including roughness, stiffness, abrasion resistance, crease recovery, tensile strength and elongation at break, were enhanced by the reinforcement treatment. In general, these properties increased with increasing $\mathrm{CNC}$ concentration, regardless of the type used.

CNC deposition on regenerated cellulose fibers was evaluated to create RCF-based composites with hierarchical structures. Fibers treated with $\mathrm{CNC}$ using $\gamma$ methacryloxypropyltrimethoxysilane (MPS) as a coupling agent absorbed two times less water than untreated fibers and enhanced the fibreepoxy resin adhesion at RH $64 \%{ }^{83}$

\section{DYE REMOVAL}

Thousands of tons of synthetic dyes are annually produced in the textile industry. These dyes are classified according to their application and chemical structure of the chromophor groups, which are responsible for the dye color. It is assumed that dye losses can vary from 2 to $50 \%$ of the initial concentration while dyeing, depending on the dye class. ${ }^{84}$ The release of dyes in large quantities into the aquatic environment causes serious damage. The presence of dyes in water, even at low concentrations, is highly visible, reduces light penetration, and negatively affects the photosynthesis of water systems. In terms of toxicity, these substances can be teratogenic, mutagenic, and carcinogenic. ${ }^{18}$ Owing to the high water consumption of textile dyeing and finishing, which is related to effluent generation in large volumes with potentially toxic composition, the textile industry has been classified as the most polluting industrial sector.

Various physical, chemical and biological treatments have been proposed for the removal or remediation of dyes from textile effluents to reduce environmental impacts. Among the different techniques, adsorption is known for its low cost, simple operation and high efficiency. ${ }^{18}$ The adsorption consists in fixing molecules, atoms, or ions in a dissolved state in vacant sites on the substrate surface by physical processes (physisorption) and chemical bonds (chemisorption). Recently, several studies have focused on the development of non-conventional low-cost adsorbents, including waste materials from agriculture and industry. ${ }^{85}$

CNCs have attracted attention as adsorbents for cationic and anionic textile dyes. In addition to the high aspect ratio, large specific surface area, biodegradability, and low toxicological risk, the presence of negative charge on the CNC surface facilitates the adsorption of positively charged dyes. ${ }^{86}$ In general, the adsorption capacity increases with an increase in the CNC amount as an adsorbent, which can be attributed to the presence of more active sites for the same number of molecules. ${ }^{86,87}$ The versatility of $\mathrm{CNC}$ as an adsorbent for cationic and anionic dyes arises from the possibility of chemical modification and functionalization. Conventional approaches to the surface modification of $\mathrm{CNCs}$ include sulfonation, esterification, etherification, silylation, and polymer grafting. ${ }^{88}$ The modification of cellulose nanomaterials for improved adsorption was recently reviewed by Köse $e t$ $a .^{17}$

The introduction of carboxyl groups onto the CNC surface increases the adsorption ability of cationic dyes, as it increases the number of adsorption sites and the electrostatic interactions between the negative carboxyl groups and positively charged cationic dye molecules. $^{18,86,89}$ Carboxylation via esterification with maleic anhydride and succinic anhydride, ${ }^{88}$ via TEMPO oxidation, ${ }^{86}$ and ammonium persulfate oxidation (APS) ${ }^{89}$ showed good results for cationic dye adsorption. Song et al. ${ }^{90}$ increased the carboxyl content on the CNC surface using ascorbic acid and citric acid as branching groups. The approach of $\mathrm{Yu}$ et $a l^{87}$ for the preparation of 
carboxylated CNCs involved single-step citric/hydrochloric acid hydrolysis.

For comparison, Table 3 shows the methylene blue absorption capacity of materials commonly used as adsorbents and others, including nanocellulose, with data obtained from different studies.

Adsorption is a complicated process that depends on several factors, such as electrostatic and/or non-electrostatic (hydrophobic) interactions and pore structure.
Commercial activated carbon is the preferred adsorbent for color removal, but it is expensive. As revised by Rafatullah et al., ${ }^{85}$ the adsorption capacities of commercial activated carbons and coals for methylene blue range from $<10$ to $\sim 1000 \mathrm{mg} / \mathrm{g}$, the majority having capacities between 200 and $400 \mathrm{mg} / \mathrm{g}$. Two studies involving nanocellulose exhibited an adsorption capacity of $800 \mathrm{mg} / \mathrm{g},{ }^{86,92}$ demonstrating the enormous potential of nanocellulose as an adsorbent.

Table 3

Comparison of adsorption capacities of NCC and other adsorbents for methylene blue

\begin{tabular}{lcc}
\hline Adsorbent & $\begin{array}{c}\text { Maximum adsorption capacity } \\
\mathrm{q}_{\max }(\mathrm{mg} / \mathrm{g})\end{array}$ & Ref. \\
\hline Commercial activated carbon & 980.3 & {$[91]$} \\
NCC-carboxymethyl chitosan aerogel & 785 & {$[92]$} \\
TEMPO-CNC & 769 & {$[86]$} \\
TEMPO-periodate-hypochlorite oxidation CNF & 502 & {$[93]$} \\
(TPC-CNF) & & \\
Microporous fish waste-based activated carbon & 476.2 & {$[94]$} \\
material (MFC) & 476.2 & {$[95]$} \\
Hazelnut husk-activated carbon & 415.8 & {$[96]$} \\
Coffee husk waste & 402.2 & {$[97]$} \\
Porous carbon from tea waste & 256.4 & {$[98]$} \\
CNC-alginate hydrogel bead & 242.3 & {$[99]$} \\
Agar/ -carrageenan hydrogel & 227.3 & {$[100]$} \\
Citrus limetta peel & 222.2 & {$[101]$} \\
Sago pith CNF aerogel & 118 & {$[86]$} \\
CNC & 116.2 & {$[102]$} \\
PMVEMA/PEG/CNC aerogel & 110.5 & {$[103]$} \\
CNC/polyurethane foam & 101 & {$[89]$} \\
NCC & 64.9 & {$[104]$} \\
CNC-ZnO nanocomposite & & \\
\hline
\end{tabular}

The increased number of adsorption sites in $\mathrm{CNC}$ has a positive impact when it is associated with hydrogels. Mohammed et al. ${ }^{98}$ impregnated $\mathrm{CNCs}$ into alginate hydrogel beads and reported that methylene blue removal was almost three times higher than that of hydrogel beads without CNCs. In addition, the removal efficiency remained at $\sim 97 \%$ after five adsorption-desorption cycles. Aerogels, which are flexible and highly porous, usually derived by freeze-drying, are promising materials for dye removal. To improve their structural stability and mechanical performance, $\mathrm{CNC}$ aerogels can be cross-linked. $^{102}$ Yang et al. $^{92}$ prepared an aerogel based on $\mathrm{CNC}$ and carboxymethylchitosan by a Schiff base reaction and obtained a maximum adsorption capacity of $785 \mathrm{mg} / \mathrm{g}$, which retained the adsorption capacity over a wide $\mathrm{pH}$ range for at least six cycles, demonstrating excellent reusability.

The adsorption of anionic dyes is also possible by the insertion of cationic groups onto the backbone of CNCs, such as imidazolium and primary amino groups. ${ }^{105,106}$ The hydroxyl groups on the surface of cellulose nanofibrils can be converted to quaternary ammonium groups using glycidyltrimethylammonium chloride, resulting in a high cationic charge density for the adsorption of anionic dyes Congo red and acid green $25 .{ }^{107}$

\section{TEXTILE FINISHING Improvement in dyeing}

In addition to the potential for removing textile dyes, NCC can play an important role in more sustainable dyeing and minimizing the environmental pollution caused by the textile 
industry. Kim et $a l .{ }^{108}$ reported an environment-friendly textile dyeing technology based on CNF that reduces the use of water and chemicals in textile dyeing by one order of magnitude. This process involves coated and anchored CNF-carboxymethyl cellulose-based hydrogels bearing reactive dye molecules on the surface of cotton fibers. Comparable dyeing and colorfastness performance to conventional exhaust dyeing was obtained with this approach using only $10 \%$ water, salt, and alkali. Liyanapathiranage et al. ${ }^{109}$ demonstrated that post-treatment of CNF-colored cotton textiles with polycarboxylic acid promotes grafting and chemical cross-linking of the CNF dye and cotton fabric surface by esterification. This offers up to $30 \%$ improvement in reactive dye fixation and up to $60 \%$ reduction in dye discharge.

Chattopadhyay and Patel ${ }^{110}$ prepared NCC from viscose rayon yarns and applied it to a polyester fabric by the padding technique. NCC treatment improves the load-bearing capacity and absorbency of the fiber. Polyester treatment enhances the color strength of the polyester fabric dyed with direct dyes and improves the speed towards soaping.

According to Minko et al., ${ }^{111}$ a nanocellulose solution may be employed to permanently bind dye to textile surfaces as a uniform thin film, with binding forces much higher than those in conventional dyeing. They produced nanocellulose (CNF and CNC) dye dispersion and applied it to cotton fabrics. Compared to the cotton control dyed by the exhaustion method, CNF and CNC presented three- and two-fold larger dye fixations.

\section{Release of fragrance}

Finishing textiles with fragrances is highly attractive and can result in value-added products. In addition to the sensory aspect, which refers to the feeling of well-being and freshness in the wearer, the essential oils used for the aroma finish can therapeutically act against stress, anxiety, depression, and irritability. ${ }^{112}$ One of the significant challenges in obtaining fragrance products is the fast release of fragrance and its duration, because aromatic compounds are highly volatile.

Kuhnt et $a l .{ }^{113}$ developed an approach to slow down the release of fragrance by decorating cellulose nanocrystals with $\beta$ damascone, a compound widely used in the perfume industry. Fragrance molecules were bound to the CNC surface using a short thioeter linker, which facilitated slow fragrance release via a retro 1,4-Michael-type reaction. Cotton sheets were washed with an aqueous softener containing decorated CNCs. As a reference, the treatment was also performed using the neat compound $\beta$-damascone. After 3 days of drying under ambient conditions, the amount of fragrance released from the sheet treated with decorated $\mathrm{CNCs}$ was 80 times higher than that of the control sample. The control sample contained a low fragrance concentration owing to evaporation during drying.

\section{Hydrophilicity and hydrophobicity}

To improve the water and moisture absorption properties of polyester fabric, Zaman et al. ${ }^{29}$ treated it with a hydrophilic surface finishing agent containing cationic CNC.

CNC, cationically modified via quaternization by grafting glycidyl trimethyl ammonium chloride, (GTMAC) was used with a textile binder as a surface finishing system for polyester fabrics. This treatment increased the fabric regain by more than $500 \%$ and reduced the contact angle from $132^{\circ}$ to $42^{\circ}$, compared to the untreated PET fabric. The results of the analyses performed with the cationic-CNC were much superior to those of the unmodified-CNC, in terms of hydrophilicity, as well as durability of the treatment after multiple washing steps. ${ }^{29}$

$\mathrm{CNC}$ has also been used to mimic the lotus effect and create rough surfaces with superhydrophobicity. Cheng et al. ${ }^{114}$ obtained a superhydrophobic cotton fabric using dipcoating with cured epoxidized oil resin as a binder. The water contact angle of the cotton surface increased from $0^{\circ}$ to $157^{\circ}$ after the treatment, and the fabric was able to separate the oil/water mixture with an efficiency higher than $98 \%$. The use of CNCs represents a more sustainable and ecologically correct alternative to inorganic compounds normally used to obtain superhydrophobic textiles.

\section{CONCLUSION}

The textile industry is one of the oldest industries in the world. It is primarily based on the use of commodities and is considered as one of the most polluting industries. In the last few decades, efforts have been directed towards new products and innovations, aiming 
at high-performance fibers, functionalized and value-added products, as well as more sustainable and environmentally friendly processes. The interest in nanocellulose for textile applications has sharply increased due to their high strength, stiffness, low weight and renewability. NCC can be isolated by simple processes from a variety of resources, including pre- and post-consumption textile waste.

NCC has been applied as a reinforcing agent in a wide range of polymer matrices, mainly water-soluble polymer matrices. Significant modifications, such as chemical grafting, have been developed to overcome the limitations associated with the low thermal stability of NCC and its incompatibility with many nonpolar thermoplastics. Methods using NCC in solution, such as wet spinning and dry spinning, which do not involve high temperatures, have resulted in highly drawn fibers and improved mechanical properties under optimal conditions. However, it must be assessed whether the final properties of the fibers justify the increase in cost, time and risks associated with the solvents. Electrospinning is the most explored method for spinning the NCC solutions with various polymers, enabling the achievement of highly interconnected porous structures that are prominent for special applications. In addition to the mechanical reinforcement with small amounts of NCC, these interconnected porous structures contribute to biological features, such as biocompatibility and cell proliferation.

Functionalization and chemical modification are also responsible for the versatility of NCC as an adsorbent for cationic and anionic dyes. As adsorption is a complex process that depends on interactions and involves several variables, the dye removal capabilities of NCC have a wide range, but its capacity is similar to that of commercial adsorbents, such as activated carbon. The association of NCC with hydrogels and aerogels tended to increase the adsorption capacity. Moreover, NCC has played an important role in more sustainable dyeing, which offers better fixation of dyes, less consumption of water and chemicals, and reduced dye discharge.

In general, the research and development of finishes in the textile sector with NCC can be further explored. Each application presents unique challenges for obtaining the desired properties. The NCC source influences the preparation and properties of the final products. NCC has a great potential for textile applications owing to its sustainable appeal and unique properties. However, its expansion at the industrial level still depends on the cost reduction of its processing and standardization for safety.

ACKNOWLEDGEMENTS: The author would like to thank $\mathrm{CNPq}$ for financial support (Process 438821/2018-1).

\section{REFERENCES}

1 M. Krifa and C. Prichard, J. Text. Inst., 111, 1778 (2020), https://doi.org/10.1080/00405000.2020.1721696

2 A. K. Yetisen, H. Qu, A. Manbachi, H. Butt, M. R. Dokmeci et al., ACS Nano, 10, 3042 (2016), https://doi.org/10.1021/acsnano.5b08176

3 M. Joshi and A. Bhattacharyya, Text. Prog., 43, 155

(2011), https://doi.org/10.1080/00405167.2011.570027

4 J.-H. Kim, B. S. Shim, H. S. Kim, Y.-J. Lee, S.K. Min et al., Int. J. Precis. Eng. Manuf. - GT, 2, 197 (2015), https://doi.org/10.1007/s40684-0150024-9

5 R. J. Moon, A. Martini, J. Nairn, J. Simonsen and J. Youngblood, Chem. Soc. Rev., 40, 3941 (2011), https://doi.org/10.1039/C0CS00108B

A. Bismarck, S. Mishra and T. Lampke in "Natural Fibers, Biopolymers and Biocomposites", CRC Press, Boca Raton, $1^{\text {st }}$ ed., edited by A. K. Mohanty, M. Misra, and L. Drzal, 2005, vol. 1, pp. 55- 128

A. Walther, J. V. Timonen, I. Díez, A. Laukkanen and O. Ikkala, Adv. Mater., 23, 2924 (2011), https://doi.org/10.1002/adma.201100580

8 K. Y. Lee, J. J. Blaker and A. Bismarck, Compos. Sci. Technol., 69, 2724 (2009), https://doi.org/10.1016/j.compscitech.2009.08.016

9 J. D. P. de Amorim, K. C. de Souza, C. R. Duarte, I. da Silva Duarte, F. D. A. S. Ribeiro et al., Environ. Chem. Lett., 18, 851 (2020), https://doi.org/10.1007/s10311-020-00989-9

10 A. Kafy, H. C. Kim, L. Zhai, J. W. Kim and T. J. Kang, Sci. Rep., 7, 1 (2017), https://doi.org/10.1038/s41598-017-10649-8

11 X. Yang, X. Wang, H. Liu, Y. Zhao, S. Jiang et al., BioResources, 12, $95 \quad$ (2017), https://ojs.cnr.ncsu.edu/index.php/BioRes/article/vi ew/BioRes_12_1_95_Yang_Impact_Dimethyl_Sulf oxide_Treatment_Morphology

12 S. Rashid and H. Dutta, Ind. Crop. Prod., 154, 112627

(2020), https://doi.org/10.1016/j.indcrop.2020.112627

13 A. Kumar, Y. S. Negi, V. Choudhary and N. K. Bhardwaj, J. Mat. Phys. Chem., 2, 1 (2014), https://doi.org/10.12691/jmpc-2-1-1 
14 M. M. Á. D. Maciel, K. C. C. de Carvalho Benini, H. J. C. Voorwald and M. O. H. Cioffi, Int. J. Biol. Macromol., 126, 496 (2019), https://doi.org/10.1016/j.ijbiomac.2018.12.202

15 Z. Wang, Z. Yao, J. Zhou and Y. Zhang, Carbohyd. Polym., 157, $945 \quad$ (2017), https://doi.org/10.1016/j.ijbiomac.2018.07.055

16 R. Xiong, X. Zhang, D. Tian, Z. Zhou and C. Lu, Cellulose, 19, $1189 \quad$ (2012), https://doi.org/10.1007/s10570-012-9730-4

17 K. Köse, M. Mavlan and J. P. Youngblood, Cellulose, 27, $2967 \quad$ (2020), https://doi.org/10.1007/s10570-020-03011-1

18 H. Qiao, Y. Zhou, F. Yu, E. Wang, Y. Min et al., Chemosphere, 141, 297 (2015), https://doi.org/10.1016/j.chemosphere.2015.07.078

19 H. Kargarzadeh, J. Huang, N. Lin, I. Ahmad, M. Mariano et al., Prog. Polym. Sci., 87, 197 (2018), https://doi.org/10.1016/j.progpolymsci.2018.07.008 20 X. Xu, F. Liu, L. Jiang, J. Y. Zhu, D. Haagenson et al., ACS Appl. Mater. Interfaces, 5, 2999 (2013), https://doi.org/10.1021/am302624t

21 O. Nechyporchuk, M. N. Belgacem and J. Bras, Ind. Crop. Prod., 93, 2 (2016), https://doi.org/10.1016/j.indcrop.2016.02.016

22 Y. Xue, Z. Mou and H. Xiao, Nanoscale, 9, 14758

(2017), https://doi.org/10.1039/C7NR04994C

23 H. Xie, H. Du, X. Yang and C. Si, Int. J. Polym. Sci., 2018, ID $7923068 \quad$ (2018), https://doi.org/10.1155/2018/7923068

24 S. Ghasemi, M. Tajvidi, D. W. Bousfield and D. J. Gardner, Ind. Crop. Prod., 111, 471 (2018), https://doi.org/10.1016/j.indcrop.2017.11.016

${ }^{25}$ H. Lee, J. Sundaram, L. Zhu, Y. Zhao and S. Mani, Carbohyd. Polym., 181, 506 (2018), https://doi.org/10.1016/j.carbpol.2017.08.119

26 S. P. Lin, I. L. Calvar, J. M. Catchmark, J. R. Liu, A. Demirci et al., Cellulose, 20, 2191 (2013), https://doi.org/10.1007/s10570-013-9994-3

27 G. F. Picheth, C. L. Pirich, M. R. Sierakowski, M. A. Woehl, C. N. Sakakibara et al., Int. J. Biol. Macromol., $\quad \mathbf{1 0 4}, \quad 97 \quad$ (2017), https://doi.org/10.1016/j.ijbiomac.2017.05.171

28 C. Clemons, J. Renew. Mater., 4, 327 (2016), https://doi.org/10.7569/JRM.2016.634112

29 M. Zaman, H. Liu, H. Xiao, F. Chibante and Y. Ni, Carbohyd. Polym., 91, 560 (2013), https://doi.org/10.1016/j.carbpol.2012.08.070

30 Q.-Y. Cheng, C.-S. Guan, M. Wang, Y.-D Li and J.-B. Zeng, Carbohyd. Polym., 199, 390 (2018), https://doi.org/10.1016/j.carbpol.2018.07.046

31 M. J. John, R. Anandjiwala, K. Oksman and A. P. Mathew, J. Appl. Polym. Sci., 127, 274 (2013), https://doi.org/10.1002/app.37884

32 R. Zhu, V. Yadama, H. Liu, R. J. Lin and D. P. Harper, Compos. Part A - Appl. S., 97, 111 (2017), https://doi.org/10.1016/j.compositesa.2017.02.025

33 C. M. Clarkson, S. M. El Awad Azrak, R. Chowdhury, S. N. Shuvo, J. Snyder et al., ACS
Appl. Polym. Mater., 1, $160 \quad$ (2018), https://doi.org/10.1021/acsapm.8b00030

34 A. Mujica-Garcia, S. Hooshmand, M. Skrifvars, J. M. Kenny, K. Oksman et al., RSC Adv., 6, 9221 (2016), https://doi.org/10.1039/C5RA22818B

35 A. Redondo, S. Chatterjee, P. Brodard, L. T. Korley, C. Weder et al., Polymers, 11, 1912 (2019), https://doi.org/10.3390/polym11121912

36 T. Rosén, B. S. Hsiao and L. D. Söderberg, $A d v$. Mater., $\quad 33, \quad 2001238 \quad$ (2020), https://doi.org/10.1002/adma.202001238

37 S. Hooshmand, S. W. Cho, M. Skrifvars, A. Mathew and K. Oksman, Plast. Rubber Compos., 43, $15 \quad$ (2014), https://doi.org/10.1179/1743289813Y.0000000066

38 J. J. Blaker, K. Y. Lee, M. Walters, M. Drouet and A. Bismarck, React. Funct. Polym., 85, 185 (2014),

https://doi.org/10.1016/j.reactfunctpolym.2014.09.0 06

39 T. Aouat, M. Kaci, E. Devaux, C. Campagne, A. Cayla et al., Adv. Polym. Technol., 37, 1193 (2018), https://doi.org/10.1002/adv.21779

40 J. Zhang, M.-C. Li, X. Zhang, S. Ren, L. Dong et al., Cellulose, 26, $4301 \quad$ (2019), https://doi.org/10.1007/s10570-019-02379-z

${ }_{41}$ J. Zhang, Q. Wu, M.-C. K. Song, X. Sun et al., ACS Sustain. Chem. Eng., 5, 7439 (2017), https://doi.org/10.1021/acssuschemeng.7b02033

${ }^{42}$ S. Hooshmand, Y. Aitomäki, M. Skrifvars, A. P. Mathew and K. Oksman, Cellulose, 21, 2665 (2014), https://doi.org/10.1007/s10570-014-0269-4

43 S. X. Peng, H. Chang, S. Kumar, R. J. Moon and J. P. Youngblood, Cellulose, 23, 1825 (2016), https://doi.org/10.1007/s10570-016-0912-3

44 I. T. Garces, S. Aslanzadeh, Y. Boluk and C. Ayranci, J. Therm. Comp. Mat., 33, 377 (2020), https://doi.org/10.1177/0892705718806334

${ }_{45}$ R. Endo, T. Saito and A. Isogai, Polymer, 54, 935

https://doi.org/10.1016/j.polymer.2012.12.035

46 E. E. Ureña-Benavides and C. L. Kitchens, Mol. Cryst. Liq. Cryst., 556, $275 \quad$ (2012), https://doi.org/10.1080/15421406.2012.635977

47 X. Ma, R. Li, X. Zhao, Q. Ji, Y. Xing et al., Compos. Part A - Appl. S., 96, 155 (2017), https://doi.org/10.1016/j.compositesa.2017.02.021

48 V. Hynninen, P. Mohammadi, W. Wagermaier, S. Hietala, M. B. Linder et al., Eur. Polym. J., 112, 334

(2019),

https://doi.org/10.1016/j.eurpolymj.2018.12.035

49 O. Nechyporchuk and T. Köhnke, ACS Sustain. Chem. Eng., 7, $1419 \quad$ (2018), https://doi.org/10.1021/acssuschemeng.8b05136

50 L. Liu, X. Yang, H. Yu, C. Ma and J. Yao, RSC Adv., 4, $\quad 14304 \quad$ (2014), https://doi.org/10.1039/C4RA01284D

51 S. Chen, G. Schueneman, R. B. Pipes, J. Youngblood and R. J. Moon, Biomacromolecules, 
15 ,

https://doi.org/10.1021/bm501161v

52 H. Chang, J. Luo, H. C. Liu, A. A. B. Davijani, P-H. Wang et al., Polymer, 122, 332 (2017), https://doi.org/10.1016/j.polymer.2017.06.072

53 C. M. Clarkson and J. P. Youngblood, Green Mater. 6 6

(2018),

https://doi.org/10.1680/jgrma.17.00027

54 S. Shrestha, F. Montes, G. T. Schueneman, J. F. Snyder and J. P. Youngblood, Compos. Sci. Technol., $\quad 167, \quad 482 \quad$ (2018), https://doi.org/10.1016/j.compscitech.2018.08.032

55 H. Dong, K. E. Strawhecker, J. F. Snyder, J. A. Orlicki, R. S. Reiner et al., Carbohyd. Polym., 87, 2488

https://doi.org/10.1016/j.carbpol.2011.11.015

56 E. Mele, J. Mater. Chem. B, 4, 4801 (2016), https://doi.org/10.1039/C6TB00804F

57 M. S. Sukiman, A. Andriyana, B. C. Ang and H. S. C. Metselaar, Polym. Test., 81, 106218 (2020), https://doi.org/10.1016/j.polymertesting.2019.1062 18

58 N. Naseri, A. P. Mathew, L. Girandon, M. Fröhlich and K. Oksman, Cellulose, 22, 521 (2015), https://doi.org/10.1016/j.polymertesting.2019.1062 18

59 Y. Wang and L. Chen, ACS Appl. Mater. Interfaces, $\quad \mathbf{6}, \quad 1709 \quad$ (2014), https://doi.org/10.1021/am404624z

60 L. Jiang, K. Li, H. Yang, X. Liu, W. Li et al., Cellulose, 27, $955 \quad$ (2020), https://doi.org/10.1007/s10570-019-02830-1

61 N. D. Wanasekara, R. P. O. Santos, C. Douch, E. Frollini and S. J. Eichhorn, J. Mater. Sci., 51, 218 (2016), https://doi.org/10.1007/s10853-0159409-y

62 B. Jia, Y. Li, B. Yang, D. Xiao, S. Zhang et al., Cellulose, $\quad 20, \quad 1911 \quad$ (2013), https://doi.org/10.1007/s10570-013-9952-0

63 D. Ponnamma, H. Parangusan, A. Tanvir and M. A. A. AlMa'adeed, Mater. Des., 184, 108176 (2019) https://doi.org/10.1016/j.matdes.2019.108176 64 B. S. Lalia, E. Guillen, H. A. Arafat and R. Hashaikeh, Desalination, 332, 134 (2014), https://doi.org/10.1016/j.desal.2013.10.030

65 X. Wang, W. Cheng, D. Wang, X. Ni and G. Han, J. Membr. Sci., 575, 71 (2019), https://doi.org/10.1016/j.memsci.2018.12.057

66 A. J. Sayyed, N. A. Deshmukh and D. V. Pinjari, Cellulose, 26, $2913 \quad$ (2019), https://doi.org/10.1007/s10570-019-02318-y

${ }_{7}$ H. Qi, C. Chang and L. Zhang, Cellulose, 15, 779 (2008), https://doi.org/10.1007/s10570-0089230-8

68 T. Heinze and T. Liebert, Prog. Polym. Sci., 26, 1689 (2001), https://doi.org/10.1016/S00796700(01)00022-3
69 S. Chrapava, D. Touraud, T. Rosenau, A. Potthast and W. Kunz, Phys. Chem. Chem. Phys., 5, 1842 (2003), https://doi.org/10.1039/B212665F

70 A. Isogai and R. H. Atalla, Cellulose, 5, 309 (1998), https://doi.org/10.1023/A:1009272632367

71 S. Zhu, Y. Wu, Q. Chen, Z. Yu, C. Wang et al., Green Chem., $\quad \mathbf{8 ,} 325 \quad$ (2006), https://doi.org/10.1039/B601395C

72 J. Araki and M. Miyayama, Polymer, 188, 122116 (2020) https://doi.org/10.1016/j.polymer.2019.122116

73 S. Iwamoto, A. Isogai and T. Iwata, Biomacromolecules, $\quad$ 12, $831 \quad$ (2011), https://doi.org/10.1021/bm101510r

74 Y. Shen, H. Orelma, A. Sneck, K. Kataja, J. Salmela et al., Cellulose, 23, 3393 (2016), https://doi.org/10.1007/s10570-016-1044-5

75 S. Hooshmand, Y. Aitomäki, N. Norberg, A. P. Mathew and K. Oksman, ACS Appl. Mater. Interfaces, $\quad \mathbf{7 ,} \quad 13022 \quad$ (2015) https://doi.org/10.1021/acsami.5b03091

76 Y. Chen, B. Geng, J. Ru, C. Tong, H. Liu et al., Cellulose, 24, $4831 \quad$ (2017), https://doi.org/10.1007/s10570-017-1478-4

77 M. J. Lundahl, A. G. Cunha, E. Rojo, A. C. Papageorgiou, L. Rautkari et al., Sci. Rep., 6, 1 (2016), https://doi.org/10.1038/srep30695

78 M. J. Lundahl, V. Klar, L. Wang, M. Ago and O. J. Rojas, Ind. Eng. Chem. Res., 56, 8 (2017), https://doi.org/10.1021/acs.iecr.6b04010

79 J. Yao, S. Chen, Y. Chen, B. Wang, Q. Pei et al., ACS Appl. Mater. Interfaces, 9, 20330 (2017), https://doi.org/10.1021/acsami.6b14650

${ }^{80}$ H. Tang, N. Butchosa and Q. Zhou, Adv. Mater., 27, 2070

(2015), https://doi.org/10.1002/adma.201404565

81 K. M. Håkansson, A. B. Fall, F. Lundell, S. Yu, C. Krywka et al., Nat. Commun., 5, 4018 (2014), https://doi.org/10.1038/ncomms5018

${ }^{82}$ A. Hebeish, S. Farag, S. Sharaf and T. I. Shaheen, J. Text. Inst., 109, 186 (2018), https://doi.org/10.1080/00405000.2017.1335377

83 A. Hajlane, R. Joffe and H. Kaddami, Cellulose, 25, 1783 (2018), https://doi.org/10.1007/s10570018-1680-z

${ }^{84}$ G. A. R. de Oliveira, J. de Lapuente, E. Teixidó, C. Porredón, M. Borràs et al., Environ. Toxicol. Chem., $\quad 35, \quad 429 \quad$ (2016), https://doi.org/10.1002/etc.3202

${ }_{85}$ M. Rafatullah, O. Sulaiman, R. Hashim and A. Ahmad, J. Hazard. Mater., 177, 70 (2010), https://doi.org/10.1016/j.jhazmat.2009.12.047

86 R. Batmaz, N. Mohammed, M. Zaman, G. Minhas, R. M. Berry et al., Cellulose, 21, 1655 (2014), https://doi.org/10.1007/s10570-014-0168-8 ${ }^{87}$ H. Y. Yu, D. Z. Zhang, F. F. Lu and J. Yao, ACS Sustain. Chem. Eng., 4, 2632 (2016), https://doi.org/10.1021/acssuschemeng.6b00126 
88

H. E. Emam and T. I. Shaheen, J. Polym. Environ., $\quad 27, \quad 2419 \quad$ (2019) https://doi.org/10.1007/s10924-019-01533-9

89 X. He, K. B. Male, P. N. Nesterenko, D. Brabazon, B. Paull et al., ACS Appl. Mater. Interfaces, $\quad \mathbf{5}, \quad 8796 \quad$ (2013), https://doi.org/10.1021/am403222u

90 M.-L. Song, H.-Y. Yu, L.-M. Chen, J.-Y. Zhu, Y.-Y. Wang et al., ACS Sustain. Chem. Eng., 7, 6969

(2019),

https://doi.org/10.1021/acssuschemeng.8b06671

91 N. Kannan and M. M. Sundaram, Dyes Pigm., 51, 25 (2001), https://doi.org/10.1016/S01437208(01)00056-0

92 H. Yang, A. Sheikhi and T. G. Van De Ven, Langmuir, 32, $11771 \quad$ (2016), https://doi.org/10.1021/acs.langmuir.6b03084

93 R. E. Abou-Zeid, A. Salama, Z. A. Al-Ahmed, N. S. Awwad and M. A. Youssef, Cellulose Chem. Technol., $\quad 54, \quad 237 \quad$ (2020), https://doi.org/10.35812/CelluloseChemTechnol.20 20.54.25

94 Y. Wang, Q. Peng, N. Akhtar, X. Chen and Y. Huang, Water Sci. Tech., 81, 1180 (2020), https://doi.org/10.2166/wst.2020.211

95 G. Karaçetin, S. Sivrikaya and M. Imamoğlu, $J$. Anal. Appl. Pyrol., 110, 270 (2014), https://doi.org/10.1016/j.jaap.2014.09.006

96 T. H. Tran, A. H. Le, T. H. Pham, D. T. Nguyen, S. W. Chang et al., Sci. Total Environ., 725, 138325 https://doi.org/10.1016/j.scitotenv.2020.138325

97 L. Borah, M. Goswami and P. Phukan, J. Environ. Chem. Eng., 3, 1018 (2015), https://doi.org/10.1016/j.jece.2015.02.013

98 N. Mohammed, N. Grishkewich, R. M. Berry and K. C. Tam, Cellulose, 22, 3725 (2015), https://doi.org/10.1007/s10570-015-0747-3

99 O. Druman, T. G. Polat, C. Ö. Diker and S. Tunç, Int. J. Biol. Macromol., 160, 823 (2020), https://doi.org/10.1016/j.ijbiomac.2020.05.191

${ }^{100}$ S. Shakoor and A. Nasar, J. Taiwan Inst. Chem.

Eng., $\quad$ 66, $154 \quad$ (2016),

https://doi.org/10.1016/j.jtice.2016.06.009
101 J. H. Beh, T. H. Lim, J. H. Lew and J. C. Lai, Int. J. Biol. Macromol., 160, 836 (2020), https://doi.org/10.1016/j.ijbiomac.2020.05.227

${ }^{102}$ L. Liang, S. Zhang, G. A. Goenaga, X. Meng, T. A. Zawodzinski et al., Front. Chem., 8, 570 (2020), https://doi.org/10.3389/fchem.2020.00570

${ }^{103}$ S. Kumari, G. S. Chauhan and J. H. Ahn, Chem. Eng. J., 304, $728 \quad$ (2016), https://doi.org/10.1016/j.cej.2016.07.008

${ }^{104}$ O. A. Oyewo, A. Adeniyi, B. B. Sithole and M. S. Onyango, ACS Omega, 5, 18798 (2020), https://doi.org/10.1021/acsomega.0c01924

${ }^{105}$ S. Eyley and W. Thielemans, Chem. Commun., 47, 4177

(2011)

https://doi.org/10.1039/C0CC05359G

${ }^{106}$ L. Jin, W. Li, Q. Xu and Q. Sun, Cellulose, 22, 2443 (2015), https://doi.org/10.1007/s10570-0150649-4

107 A. Pei, N. Butchosa, L. A. Berglund and Q. Zhou, Soft Matter, 9, $2047 \quad$ (2013), https://doi.org/10.1039/C2SM27344F

${ }^{108}$ Y. Kim, L. T. McCoy, E. Lee, H. Lee, R. Saremi et al., Green Chem., 19, 4031 (2017), https://doi.org/10.1039/C7GC01662J

${ }^{109}$ A. Liyanapathiranage, M. J. Peña, S. Sharma and S. Minko, ACS Omega, 5, 9196 (2020), https://doi.org/10.1021/acsomega.9b04498

${ }^{110}$ D. P. Chattopadhyay and B. H. Patel, J. Text. Sci. Eng., 6, 2 (2016), http://dx.doi.org/10.4172/2165-8064.1000248

${ }^{111}$ S. Minko, S. Sharma, I. Hardin, I. Luzinov, S. Wu Daubenmire et al., Clemson Patents, 565 (2016),

https://tigerprints.clemson.edu/cgi/viewcontent.cgi? article $=1570 \&$ context $=$ clemson_patents

${ }^{112}$ N. Singh, M. Yadav, S. Khanna and O. Sahu, Sustain. Chem. Pharm., 5, 22 (2017), https://doi.org/10.1016/j.scp.2017.01.003

${ }^{113}$ T. Kuhnt, A. Herrmann, D. Benczédi, E. J. Foster and C. Weder, Polym. Chem., 6, 6553 (2015), https://doi.org/10.1039/C5PY00944H

${ }^{114}$ Q. Y. Cheng, C. S. Guan, M. Wang, Y. D. Li and J. B. Zeng, Carbohyd. Polym., 199, 390 (2018), https://doi.org/10.1016/j.carbpol.2018.07.046 